\title{
COPD patients' perspectives at the time of diagnosis: a qualitative study
}

\author{
*Mats Arne ${ }^{\mathrm{a}, \mathrm{b}}$, Margareta Emtner ${ }^{\mathrm{b}}$, Staffan Jansonn ${ }^{\mathrm{a}, \mathrm{c}}$, Bodil Wilde-Larsson ${ }^{\mathrm{d}}$ \\ a Primary Care Research Unit, County Council of Värmland, Universitetsgatan 3, SE 65637 Karlstad, Sweden \\ b Department of Medical Sciences, Respiratory Medicine and Allergology, Uppsala University, SE 75185 Uppsala, Sweden \\ c Department of Social Sciences, Division of Public Health, Karlstad University, SE 65188 Karlstad, Sweden \\ d Department of Nursing, Karlstad University, SE 65188 Karlstad, Sweden
}

Received 28th August 2006; accepted 23th February 2007

\begin{abstract}
Aims: To gain an understanding of patients' perspectives and perceptions of chronic obstructive pulmonary disease (COPD) at the time of diagnosis.

Methods: A qualitative study using grounded theory. Ten patients in primary care in Sweden, newly diagnosed with COPD or with suspected COPD, were interviewed.

Results: The analysis created a process model with a core category "Consequences of smoking" and main categories "Shame", "Appearance of symptoms", "Adaptation", "Reflection", and "Action". "Restrictions in physical capacity" was a key indicator of evolving disease and "Getting a diagnosis" was crucial for the patient.

Conclusions: The COPD patient needs a clear diagnosis at an early stage. It is important to seize the opportunity when the presumptive COPD patient is receptive towards support and further action. To detect and support the patient, health professionals must be aware of minor symptoms and underlying mechanisms of possible shame.

(c) 2007 General Practice Airways Group. All rights reserved.

M Arne, et al. Prim Care Resp J 2007; 16(4): 215-221.

doi:10.3132/pcrj.2007.00033
\end{abstract}

Keyw ords COPD, primary health care, qualitative research, shame, smoking

\section{Introduction}

Chronic obstructive pulmonary disease (COPD) is a major cause of morbidity and mortality among adults. The airflow obstruction in COPD is progressive, not fully reversible, and does not change markedly over time. ${ }^{1,2}$ COPD is usually not diagnosed until it is clinically apparent and moderately advanced; ${ }^{3,4}$ significant airflow obstruction is present before the individual is aware of the disease, and the lack of symptoms is a reason for late diagnosis. ${ }^{5}$ In addition, serious underdiagnosis of COPD is common. ${ }^{5-7}$

COPD is predominantly caused by smoking, and stopping smoking is the most effective treatment to stop disease progression ${ }^{8,9}$ It is therefore important to detect and diagnose COPD as early as possible. ${ }^{10}$ Early symptoms of COPD have previously been described as 'chronic bronchitis'," and though the term 'COPD' has been used by professionals for several decades, it has not been recognised by the general public until recently. ${ }^{12}$

There is common agreement regarding the symptoms and signs of COPD when it initially presents ${ }^{1-4}$ Early symptoms such as morning cough or shortness of breath on vigorous exertion are important indicators to be aware of. Studies of patients perspectives at this early stage have not, to our knowledge, been published. Consequently, there is a need for research on patients' views to get a better understanding of the process underlying detection of the disease. Qualitative research methods are appropriate for exploring new research areas.

The aim of this study was to gain an understanding of COPD patients' perspectives and perceptions of their disease at the time of COPD diagnosis.

\footnotetext{
* Corresponding author: Tel: +46 706533259 Fax: +46 54615953 Email: mats.arne@medsci.uu.se
} 
Table 1. Patients' characteristics.

\begin{tabular}{|c|c|c|c|c|c|c|c|c|c|c|c|}
\hline Patient & Sex & $\begin{array}{l}\text { Age } \\
\text { (yrs) }\end{array}$ & $\begin{array}{l}\text { FEV\% } \\
\left(\mathrm{FEV}_{1} /\right. \\
\mathrm{FVC}) \\
(\%)\end{array}$ & $\begin{array}{c}\mathrm{FEV}_{1} \\
(\mathrm{~L})\end{array}$ & $\begin{array}{c}\mathrm{FEV}_{1} \\
\% \text { pred } \\
(\%)\end{array}$ & $\begin{array}{l}\text { GOLD } \\
\text { stage }\end{array}$ & $\begin{array}{l}\text { Current } \\
\text { smoker }\end{array}$ & $\begin{array}{c}\text { Smoking; } \\
\text { pack- } \\
\text { years }\end{array}$ & $\begin{array}{c}\text { Start of } \\
\text { symptoms } \\
\text { (years } \\
\text { before } \\
\text { interview) }\end{array}$ & $\begin{array}{c}\text { Spirometry } \\
\text { performed } \\
\text { before } \\
\text { interview }\end{array}$ & $\begin{array}{c}\text { Diagnosis } \\
\text { of COPD } \\
\text { (months } \\
\text { before } \\
\text { interview) }\end{array}$ \\
\hline 1 & $\mathrm{~F}$ & 48 & 37 & 1.7 & 64 & ॥ & $\mathrm{N}$ & 15 & 3 & Y & $<1$ \\
\hline 2 & $M$ & 69 & 39 & 1.2 & 39 & III & Y & 37 & 2 & Y & $\mathrm{N}$ \\
\hline 3 & $F$ & 58 & 50 & 1.5 & 58 & II & Y & 33 & 10 & Y & $\mathrm{N}$ \\
\hline 4 & $F$ & 62 & 52 & 1.7 & 70 & II & Y & 23 & 10 & Y & $\mathrm{N}$ \\
\hline 6 & $\mathrm{~F}$ & 71 & 64 & 1.1 & 56 & II & N & 12 & $<1$ & $N$ & $N$ \\
\hline 7 & M & 64 & 58 & 2.8 & 86 & 1 & N & 22 & 20 & Y & 2 \\
\hline 8 & $\mathrm{~F}$ & 64 & 64 & 2.0 & 92 & I & $\mathrm{N}$ & 35 & 1 & Y & 1 \\
\hline 9 & $F$ & 57 & 67 & 2.1 & 84 & I & $Y$ & 35 & 15 & $\mathrm{~N}$ & $N$ \\
\hline 10 & $M$ & 76 & 56 & 2.3 & 86 & I & $N$ & 60 & 1 & $\mathrm{~N}$ & 3 \\
\hline
\end{tabular}

$\mathrm{F}=$ Female, $\mathrm{M}=$ Male, $\mathrm{Y}=\mathrm{Yes}, \mathrm{N}=$ No, $\mathrm{L}=$ litres, \%pred = percent predicted according to ERS reference values (Eur Respir J Suppl 1993;16:5-40)

\section{Methods}

\section{Qualitative research method - grounded theory}

The grounded theory qualitative research method according to Glaser and Strauss ${ }^{13}$ is suited to areas that have not previously been explored, since the approach allows the emergence of theory from the data. Grounded theory is an inductive method for generating hypotheses and models emerging from data. It can shed light on people's life situations and how they perceive and cope with disease. ${ }^{14}$

\section{Study population}

Patients in primary care in Sweden, newly diagnosed with COPD or diagnosed with suspected COPD, were recruited by their physician. Some patients had not yet received the diagnosis of COPD at the time of the interview; in these cases, spirometry performed after the interview confirmed the diagnosis.

Inclusion criteria were: suspected COPD, or a diagnosis of COPD within the previous year; and a minimum total tobacco consumption of 10 pack-years. Exclusion criteria were: a postbronchodilator $\mathrm{FEV}_{1} / \mathrm{FVC}$ ratio above $0.7(70 \%)$, indicating no airway obstruction according to the Global Initiative for Obstructive Lung Disease (GOLD) ${ }^{4}$ criteria; and a current diagnosis of asthma or heart disease.
Patients' characteristics are presented in Table 1. The median age was 63 years (range 48-76).

\section{Pulmonary function testing}

Spirometry was performed and summarised according to American Thoracic Society (ATS) criteria ${ }^{15}$ using a Jaeger MasterScope pneumotachograph (VIASYS, Würzburg, Germany). Both relaxed inspiratory vital capacity (VC) and forced expiratory vital capacity (FVC) manoeuvres were performed. Post-bronchodilator values after reversibility testing with $0.8 \mathrm{mg}$ salbutamol were used for classification according to GOLD criteria. ${ }^{4}$

\section{Data collection and analysis}

Data collection and analysis is a parallel process in grounded theory, where experience from previous interviews is brought forward to subsequent interviews. The patients were interviewed in-depth (by MA) in 2002-2004. The interviews, lasting between 39 to 63 minutes, were recorded and transcribed verbatim. Analysis was done continuously by MA and then regularly discussed with the other authors to check for adequacy and relation to the original data.

The opening question was: "Can you tell me something about your life in connection with your lung trouble?" The 
Figure 1. The model describing COPD patients' perspectives at the time of diagnosis and connections between categories. "Consequences of smoking" outlines the core category covering the main categories and seven subcategories.

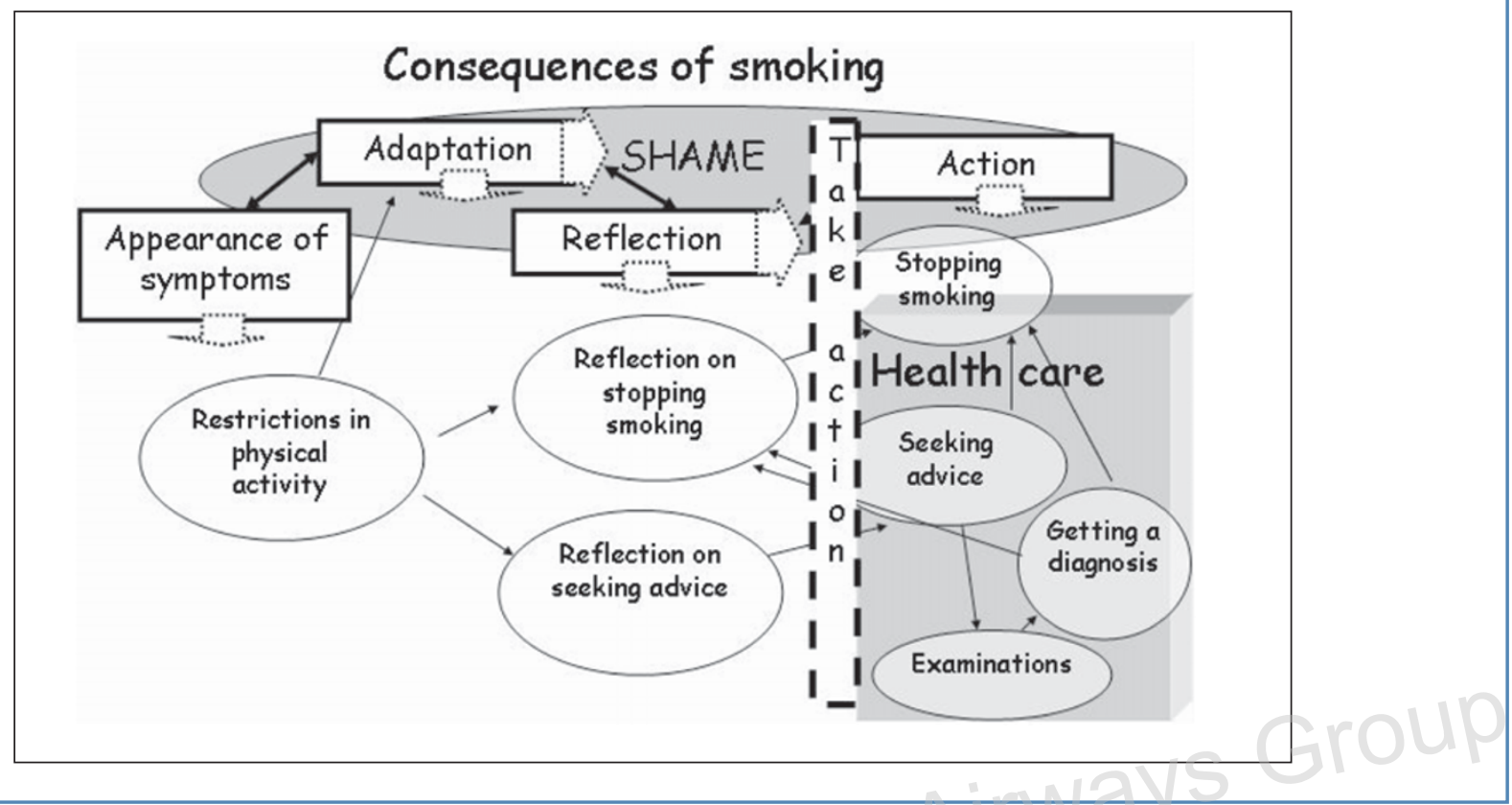

patients were free to raise the issues that were important to them. The data was coded line-by-line in the OpenCode program. ${ }^{16}$ At first, the coding was open, analysing every sentence to generate substantive codes which were then grouped into seven subcategories and five main categories. Comparisons were constantly made and memos written during the process. Thereafter, selective coding was done, focussing on a core category central to the data and related to all categories. The final theoretical coding formed a structure which integrated the categories for the purpose of building a model. Saturation was achieved after eight interviews.

All the patients provided informed consent. The study was approved by the Research Ethics Committee at Örebro Regional Hospital.

\section{Results}

The results are presented with the aid of a theoretical model (Figure 1) constructed from the data analysis. Quotations illustrate the categories (Table 2).

Consequences of smoking emerged as the core category. Five main categories Shame, Appearance of symptoms, Adaptation, Reflection and Action were defined. The core category, main categories and seven subcategories interacted and described a process.

The patients had started smoking without knowing or thinking about future consequences. Smoking continued for years before the Appearance of symptoms. One indicator of disease progression was Restrictions in physical activity.
Adaptation to the disease could appear parallel to appearance of symptoms. Reflection on smoking as a risk factor for getting a disease, including Reflection on stopping smoking and Reflection on seeking advice, was part of the process. The main category, Action, constituted active steps to seek medical advice or to deal otherwise with the disease. The presence of acute symptoms promoted the seeking of care: Take action. Getting a diagnosis was important to the patients, but also filled them with fear - for example, a fear of cancer.

\section{Shame}

Shame proved to be a main category that interacted with most others and also hindered people from taking action. Shame was evident throughout the interviews and this category emerged from the entire process during the analysis. Although not always explicit, there were statements that referred to the disease as being self-inflicted and caused by smoking. Shame was undoubtedly an obstacle to seeking advice.

\section{Appearance of symptoms}

Symptoms could be present, but were initially not recognised by the patient as signs of disease.

Appearance of symptoms was an indicator of disease progression. Initial symptoms occurred intermittently, and often in combination with upper respiratory tract infections. Symptoms such as coughing, wheezing, rattling, secretion production, and moments of difficulty in breathing, could appear. 


\section{Restrictions in physical activity}

In the beginning there were no obvious symptoms or restrictions in physical activity. As the disease progressed, physical ability decreased. Successive deterioration with more symptoms of panting and heavy breathing eventually became obvious. A sudden change - getting breathless during physical activity - was expressed as a contrast. The change in physical ability was expressed as loss of energy, a feeling of fatigue, or of becoming physically restricted compared to others.

\section{Adaptation}

Adaptation was a method to cope with symptoms, especially connected to physical activity. Avoiding or giving up physical activity were two ways of adaptation. Adjusting an activity could include slowing down the speed and intensity, or stopping during the activity and using some breathing technique. There was also an intention to hide breathlessness. Other ways of adaptation were to neglect symptoms, not recognise restrictions, and getting used to coughing in the mornings.

\section{Reflection}

Reflection on the disease occurred at different time points and could start parallel to adaptation. When starting smoking the patients were not aware of the risks of smoking. Statements about having exposed oneself voluntarily, and thereby damaging the lungs, revealed a sense of shame. This could cause delay in reflection on seeking advice. Poor physical condition, or ageing, were explanations for not being physically active.

\section{Reflection on stopping smoking}

Reflection on stopping smoking was a component of the reflection part of the process. It was influenced by the media. Earlier experience of failing to give up smoking could stop the interviewee from considering it at this stage, i.e. resignation. A factor encouraging the patients to smoke was their unawareness of disease.

\section{Reflection on seeking advice}

Reflection on seeking advice could also be delayed. Patients refrained from talking about breathing problems, or did not seek medical advice due to insufficient knowledge of COPD. They also perceived the symptoms as being too mild. Examples were given of seeking medical advice for symptoms and not being warned of the possibilities of developing a serious disease or of receiving a diagnosis of COPD (Table 2).

\section{Action}

Take action illustrates the moment when the patients were ready to do something about their situation (see Figure 1).

The subcategories Stopping smoking and Seeking advice from family, friends or health care were active steps. Support for Stopping smoking came from different sources. Encouragement from family and friends was important. Accelerating symptoms such as coughing strengthened the decision to stop smoking. Positive feedback after having stopped - e.g. disappearance of the cough and secretions, and easier breathing - helped the patients to remain smokefree.

Action was triggered by several factors. Contact with health care could lead to action such as support over Stopping smoking, Examinations or Getting a diagnosis. When acute symptoms appeared, the contact with health care could be at an emergency department or in primary care.

Some physicians never asked about smoking, while others always asked. The patients expected the physician to give an ultimate message to stop smoking.

\section{Examinations}

The most important examination from the patients' viewpoint was the chest $X$-ray. Spirometry was not known by the patients as an important test. Information about results from spirometry consisted of quantification of remaining or lost lung capacity. Knowing the results of examinations could affect attitudes to performing physical activity. The patients expected more explanation of their results. Limited information about earlier results could influence them to continue smoking (Table 2).

\section{Getting a diagnosis}

The diagnostic process was experienced as a prolonged one. There were uncertainties about a clear diagnosis, especially between asthma and COPD. When patients were informed about a COPD diagnosis, they were more willing to stop smoking.

In connection with getting the diagnosis, reflections about the future appeared. These included thoughts about worsening of symptoms, a need for oxygen support, mortality, uncertainty about their ability to stop smoking, remorse and resignation - i.e. thinking about their ability to manage various problems and go on living with the disease, but also thinking of disease progression.

\section{Discussion}

This study presents the consequences of smoking. These are related to other factors in a process model to describe COPD patients' perspectives during the process of COPD diagnosis. New knowledge about shame as an important factor influencing this process has emerged: as far as we are aware, no previous study has shown the importance of shame in connection with a diagnosis of COPD.

Symptoms of emerging COPD are absent when the process starts, and are hard to define. One problem was the difficulties in knowing when the disease had started, and what symptom to recognise as the first sign of the disease. COPD often has its roots decades before the onset of symptoms. ${ }^{8}$ Depending on how the questions are asked and patients' perceptions of symptoms, as well as their memory of past symptoms, the 
Table 2. Categories and quotations.

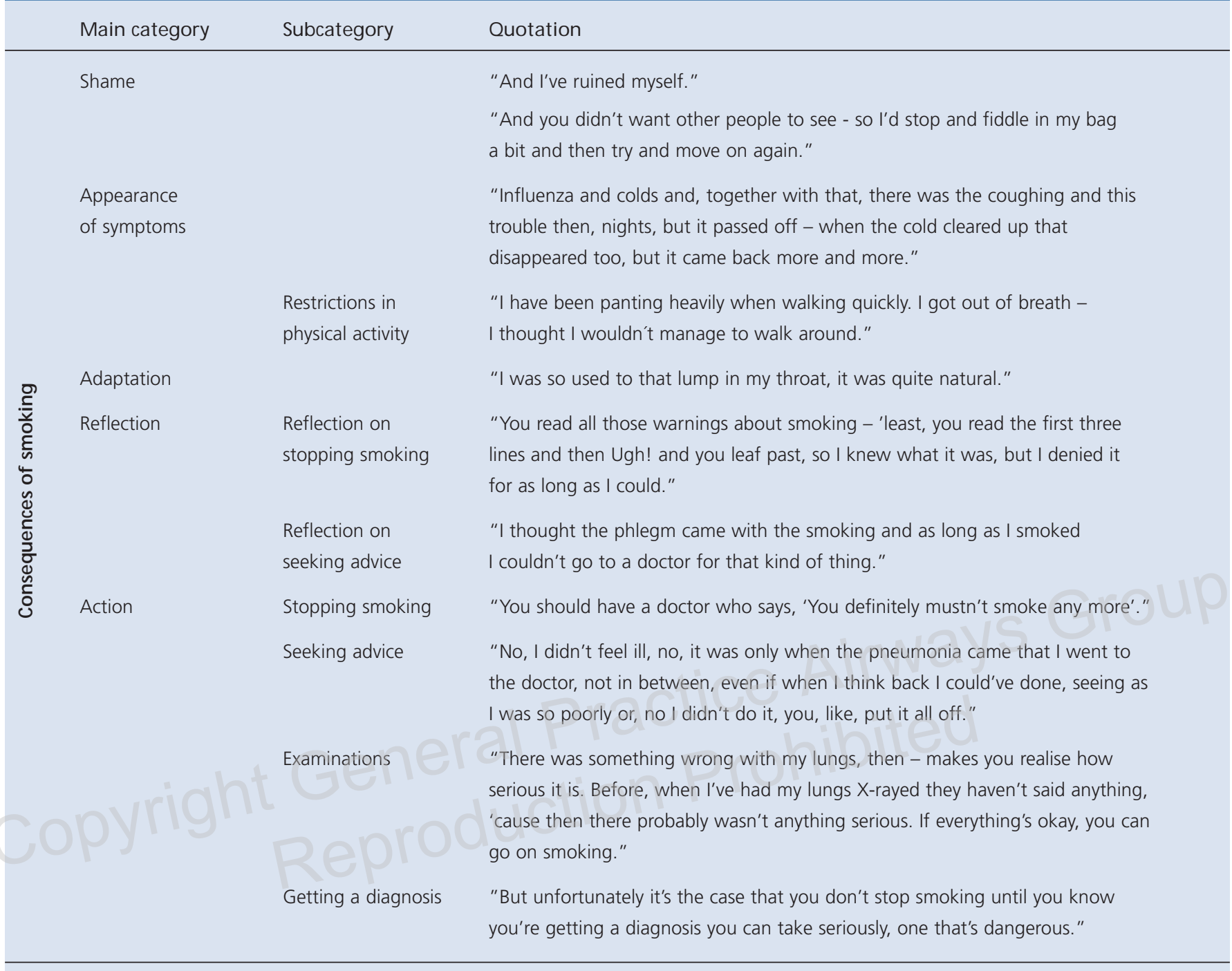

answers to questions can vary considerably - for example, regarding symptom onset (see Table 1).

Decreasing physical ability can indicate progression of the disease. The cardinal symptom - dyspnoea - can be minor because the patient adapts to lower levels of activity. A key question is about changes in physical activity.

Some strategies for handling the disease are mentioned. Early on, symptoms are minor and perhaps this is why few strategies for handling them are mentioned. In another study of older patients with daily symptoms, two major themes were described; adjusting physically to COPD, and adjusting emotionally. ${ }^{17}$

Patients' perception of symptoms as being self-inflicted leads to delay in seeking medical advice, as described previously. ${ }^{18}$ Shame is an important cause of delay in this part of the process. Connections between lung cancer and shame have been published previously, ${ }^{19}$ but this relationship has not been clearly identified for COPD before.

When action is taken, it is a result of a reflective process. Crucial moments occur when readiness for taking action is evident, e.g. when contracting pneumonia, getting acute symptoms, or successively deteriorating physical capacity. The patient's motivation to take action can be higher on these occasions, as discussed in connection with the Prochaska and DiClemente stage-of-change model. ${ }^{20}$ Lack of confidence in health care and low availability of care are obstacles to consultation. Moreover, the patient can seek primary care attention for other diseases where the need to evaluate breathing problems is less obvious and perhaps impossible during the actual consultation.

When the patient is ready to act, it is important that health care interventions and messages are accurate so that they give support. A clear message about results of examinations and a clear diagnosis are crucial if the patient is to take action - for 
example, giving up smoking. Spirometry, which is required for a definite diagnosis, was not considered interesting by the patients. Examination results are often, unfortunately, communicated to the patient without assurance as to how the message is received: not telling about or explaining a result can be interpreted as good news, or alternatively may make the patient suspect that there is something wrong. This depends on the patients' expectations, while the health professional is unaware of the possible breakdown in communication. The need for more information about the disease, as well as strategies that physicians may use to facilitate discussion of prognosis with patients with severe COPD, have been expressed in other studies. ${ }^{21-23}$

The selection of patients limits the applicability of this study to current or former smokers while COPD is being diagnosed. 'Never-smokers' can also contract COPD but this is restricted to a prevalence of about $4-5 \%$ of patients reporting physician-diagnosed COPD. ${ }^{24}$

Grounded theory requires continuous theoretical sampling to direct further data collection. Given the limited number of possible patients, sampling was mainly purposeful and intended to describe the research area. This is in line with the grounded theory concept, which "... starts in a site, without knowing what the research question or main concern is until it emerges". ${ }^{14}$ The present sampling strategies represent an adaptation to real-world conditions: the strategies meet the information needs of the study. ${ }^{25}$ Finally, although we attempted to generate categories and a model strictly from empirical data, it cannot be excluded that the authors' preconceptions may have influenced the results and conclusions of the study. Further studies are needed to shed light on this, as well as on the relative importance of the different categories identified in this study based on a limited number of informants.

\section{Conclusion}

Reflection about smoking and emotions of shame related to smoking were revealed. This can delay the moment of taking action. In practice it is of great importance to ask the patient about changes in his or her perceptions of physical ability. This is also an opportunity to identify something that patients can recognise on their own. Centres which manage patients who present with acute symptoms where the diagnosis of COPD is possible should alert the patient and the physician responsible, so that possible COPD can be investigated. Getting a diagnosis as confirmation of the developing disease is a great priority for the patients.

A clear message to health professionals is to seize the opportunity when the presumptive COPD patient is receptive towards support and further action. Health professionals also need to be aware of possible underlying shame so that they can detect and support COPD patients appropriately. This is an issue for further research.

\section{Acknow ledgements}

This study was supported by a research grant from the County Council of Värmland and the Swedish Heart and Lung Association.

\section{Conflict of interest declaration}

There are no conflicts of interest to declare.

\section{References}

1. BTS guidelines for the management of chronic obstructive pulmonary disease. The COPD Guidelines Group of the Standards of Care Committee of the BTS. Thorax 1997;52(Suppl 5):S1-28.

2. Chronic obstructive pulmonary disease. National clinical guideline on management of chronic obstructive pulmonary disease in adults in primary and secondary care. Thorax 2004;59(Suppl 1):1-232.

3. Celli BR, MacNee W. Standards for the diagnosis and treatment of patients with COPD: a summary of the ATS/ERS position paper. Eur Respir J 2004 23(6):932-46

4. Pauwels RA, Buist AS, Calverley PM, Jenkins CR, Hurd SS. Global strategy for the diagnosis, management, and prevention of chronic obstructive pulmonary disease. NHLBIMHO Global Initiative for Chronic Obstructive Lung Disease (GOLD) Workshop summary. Am J Respir Crit Care Med 2001;163(5):1256-76.

5. Siafakas $N$, Vermeire $P$, Pride $N$, et al. Optimal assessment and management of chronic obstructive pulmonary disease (COPD). The European Respiratory Society Task Force. Eur Respir J 1995;8(8):1398-420

6. Lindström M, Jonsson $E$, Larsson K, Lundbäck B. Underdiagnosis of chronic obstructive pulmonary disease in Northern Sweden. Int J Tuberc Lung Dis 2002;6(1):76-84.

7. van den Boom G, van Schayck CP, van Mollen MP, et al. Active detection of chronic obstructive pulmonary disease and asthma in the general population. Results and economic consequences of the DIMCA program. Am J Respir Crit Care Med 1998;158(6):1730-8.

8. Anto JM, Vermeire P, Vestbo J, Sunyer J. Epidemiology of chronic obstructive pulmonary disease. Eur Respir J 2001;17(5):982-94.

9. van der Meer RM, Wagena EJ, Ostelo RW, Jacobs JE, van Schayck CP. Smoking cessation for chronic obstructive pulmonary disease. Cochrane Database Syst Rev 2003(2):CD002999

10. Calverley PM. COPD: early detection and intervention. Chest 2000;117(5 Supp 2):365S-371S

11. Fletcher CM, Elmes PC, Fairbairn AS, Wood CH. The significance of respiratory symptoms and the diagnosis of chronic bronchitis in a working population. $\mathrm{Br}$ Med J 1959;2(5147):257-66

12. Lundbäck B, Gulsvik A, Albers M, et al. Epidemiological aspects and early detection of chronic obstructive airway diseases in the elderly. Eur Respir J Suppl 2003; $40: 3 s-9 s$.

13. Glaser BG, Strauss AL. The discovery of grounded theory: strategies for qualitative research. Chicago: Aldine, 1967. p.1-271.

14. Glaser BG. Basics of grounded theory analysis : emergence vs forcing. Mil Valley, Calif.: Sociology Press, cop., 1992. p. 1-129.

15. Standardization of Spirometry, 1994 Update. American Thoracic Society. Am J Respir Crit Care Med 1995;152(3):1107-36.

16. OpenCode [program]. 2.1 June 2001 version. Umeå: UMDAC and Epidemiology, Department of Public Health and Clinical Medicine at Umeå University, Sweden, 2001

17. Cicutto L, Brooks D, Henderson K. Self-care issues from the perspective of individuals with Chronic Obstructive Pulmonary Disease. Patient Educ Couns 2004;55(2):168-76.

18. Kornmann O, Beeh KM, Beier J, Geis UP, Ksoll M, Buhl R. Newly diagnosed 
chronic obstructive pulmonary disease. Clinical features and distribution of the novel stages of the Global Initiative for Obstructive Lung Disease. Respiration 2003; 70(1):67-75.

19. Chapple A, Ziebland S, McPherson A. Stigma, shame, and blame experienced by patients with lung cancer: qualitative study. $\mathrm{Br}$ Med J 2004; 328(7454):1470.

20. Prochaska JO, DiClemente CC. Stages and processes of self-change of smoking: toward an integrative model of change. J Consult Clin Psychol 1983; 51(3):390-5.

21. Robinson T. Living with severe hypoxic COPD: the patients' experience. Nurs Times 2005;101(7):38-42.
22. Curtis JR, Wenrich MD, Carline JD, Shannon SE, Ambrozy DM, Ramsey PG. Patients' Perspectives on Physician Skill in End-of-Life Care*: Differences Between Patients With COPD, Cancer, and AIDS. Chest 2002;122(1):356-62.

23. Halliwell J, Mulcahy P, Buetow S, Bray Y, Coster G, Osman LM. GP discussion of prognosis with patients with severe chronic obstructive pulmonary disease: a qualitative study. Br J Gen Pract 2004;54(509):904-08.

24. Weiss ST, DeMeo DL, Postma DS. COPD: problems in diagnosis and measurement. Eur Respir J Suppl 2003;41:4s-12s.

25. Coyne IT. Sampling in qualitative research. Purposeful and theoretical sampling; merging or clear boundaries? J Adv Nurs 1997;26(3):623-30.

\section{Available online at http://w w w.thepcrj.org}

